\title{
Is sexual education an important skill to teach in medical schools?
}

\author{
Fernando Nestor Facio Jr ${ }^{1,2,3}$, Maria Fernanda W. Facio ${ }^{4}$ \\ ${ }^{1}$ Department of Urology, Medical School of São José do Rio Preto (FAMERP), Sao Jose do Rio Preto, SP, Brazil; ${ }^{2}$ Head of Men's Health, Outpatient \\ Clinic of Hospital de Base, São Jose Rio Preto, SP, Brazil; ' 3 exual Medicine, Johns Hopkins University, Baltimore, USA; ${ }^{4}$ Medical School FACERES, \\ São Jose Rio Preto, SP, Brazil \\ Correspondence to: Fernando Nestor Facio Jr, MD, PhD. Department of Urology, São José do Rio Preto Medical School, São José do Rio Preto, Ave. \\ Fernando C. Pires 3600, São Jose Rio Preto-SP, São Paulo, Brazil. Email: fnfacio@yahoo.com.br.
}

Submitted Jun 29, 2018. Accepted for publication Jul 08, 2018.

doi: $10.21037 /$ tau.2018.07.05

View this article at: http://dx.doi.org/10.21037/tau.2018.07.05

Most medical students are interested in education about sexual medicine in the practice and they believe that sexual medicine should be included in medical school curricula (1). Due to the growing need for medical care for problems related to human sexuality, it has been-recommended that sexual medicine can be considered in medical courses. Based on these suggestions, sexual medicine should be taught using a multidisciplinary approach throughout the course. Furthermore, medical care providers have lacked qualification and understanding about sexual medicine and patients have criticized physicians because they rarely address sexuality issues $(1,2)$.

Recently, medical students in Brazil reported that the quality of sexual medicine instruction is insufficient with more than half of the students feeling that they do not have enough knowledge about human sexuality for their future positions as medical care providers (2).

Hence, the time allocated to teaching sex education in undergraduate medical courses is often unsatisfactory to prepare doctors for their roles in treating sexual health problems which results in substantial dissatisfaction among medical students (3).

This lack of preparation may be reflected in the daily clinical practice (3). One study shows that more than $90 \%$ of patients expect the doctor to initiate discussions on sexual health issues (4).

This proves to be an important and fertile field to be developed in order to improve the expertise of professionals by the incorporation of discussions about sexual health in their medical training. In addition to medical education on pathological sexuality, future educational targets should include more discussions on healthy sexuality and its sociocultural significance. In this way, students' wishes would be met and health care providers in all areas would be able to provide impartial, holistic and sensitive treatment of sexual problems.

Sexual medicine has grown considerably as a specialty over the last 20 years, however regulatory aspects of training, assessment and certification are currently incipient and, in many respects, lagging behind scientific and clinical knowledge on the issue (5).

There is interest in developing norms for the training of health professionals aimed at offering knowledge and facilitating learning, thereby enriching curricula and improving standards of care provided by physicians and health professionals involved in sexual medicine in undergraduate sexual medicine programs throughout the world (5).

\section{Acknowledgements}

None.

\section{Footnote}

Conflicts of Interest: The authors have no conflicts of interest to declare.

\section{References}

1. Coleman E, Elders J, Satcher D, et al. Summit on medical school education in sexual health: report of an expert consultation. J Sex Med 2013;10:924-38.

2. Facio FN Jr, Glina S, Torres LO, et al. Educational 
program on sexual medicine for medical students: pilot project in Brazil. Transl Androl Urol 2016;5:789-93.

3. Marwick C. Survey says patients expect little physician help on sex. JAMA 1999;281:2173-4.

4. Ende J, Kazis L, Ash A, et al. Measuring patients' desire for autonomy: decision making and information-seeking

Cite this article as: Facio FN Jr, Facio MF. Is sexual education an important skill to teach in medical schools? Transl Androl Urol 2018;7(4):730-731. doi: 10.21037/tau.2018.07.05 preferences among medical patients. J Gen Intern Med 1989;4:23-30.

5. Eardley I, Reisman Y, Goldstein S, et al. Existing and Future Educational Needs in Graduate and Postgraduate Education. J Sex Med 2017;14:475-85. 